\title{
Study the Effect of Cold Plasma on the Nonlinear Properties of Polymeric Membranes Rod Amine (R3Go)
}

\author{
Rajaa N.keta $^{1^{*}} \quad$ Hamed H.Marbet ${ }^{1} \quad$ Hanaa Mohammed Yaseen ${ }^{1}$ \\ Slafa I. Ibrahim ${ }^{2}$ \\ Shemaa S.Mahdi
}

Received 21/11/2017, Accepted 2/1/2019, Published 11/3/2019

This work is licensed under a Creative Commons Attribution 4.0 International License.

\begin{abstract}
:
The nonlinear optical properties for polymeric (PMMA) doping with dye Rhodmine (R3Go) has been studied .The samples are prepared by normal polymerization method with concentrations of $5 \times 10^{-5} \mathrm{~mol} / 1$ and a thickness of $272.5 \mu \mathrm{m}$.

Plasma effect was studied on samples prepared before and after exposure to the Nd: YAG laser for three times 5, 10 and 15 minutes. Z-Scan technique is used to determine the nonlinear optical properties such as; refractive index $\left(\mathrm{n}_{2}\right)$ and the coefficient of nonlinear absorption $(\beta)$. It was found that the nonlinear properties is change by increasing of plasma exposure time, this result gives good indication about the effect of plasma on the internal structure of the polymer.
\end{abstract}

Key words: Dielectric Barrier Discharge (DBD), Nd:YAG laser, Non-linear properties, Z-scan

\section{Introduction:}

Plasma whose electrons are drowns away from their atoms. A continuous fed of energy is necessary to keep away electrons from their atoms. When the energy is stopped, then the electrons can recombine and the plasma is converted to gas once again. The plasma can exist in a varying range of temperatures without changing its state.

Plasma state does not have any particular shape and resembles gas without a vessel. The different between plasma and ordinary gases, due to its property of being controlled by electromagnetic fields, which can change its shape form into another useful shaped structures.(1)

Plasmas can be classified according to the relative temperature of Ions", neutral atom and electrons as "thermal" or "non-thermal. In case of "Thermal plasma", the heavy particles and the electrons are at same temperature, i.e., they are in thermal equilibrium. While electrons in Nonthermal plasmas are much hotter than the heavy particles, which are at a much lower temperature. WhenAtmospheric plasma temperature is $40{ }^{\circ} \mathrm{C}$ or less is considered Cold Atmospheric plasma (CAP). Gases that can be used to produce CAP are Helium, Argon, Nitrogen, Heliox (amix of helium and oxygen), and air (2).

\footnotetext{
'Physics Department, College of Science for Women, University of Baghdad, Baghdad, Iraq.

${ }^{2}$ Energy and Renewable Energies Technology Center, University of Technology, Baghdad, Iraq.

*Corresponding author: rajaanadir2006@gmail.com
}

Nonlinear optics deals with interaction of laser with matter, when laser beam falling on the transparent circles change the refractive index and absorption coefficient. These characteristics are called nonlinear optical properties (3). These properties are important variables in the identification and determination of the application of any material in the nonlinear optical instrument. Where the technique isZ-Scan, this technique is discovered by the Indian scientist (sheik-Bahae, 1989 ) it is used for describing nonlinear variables (refractive index and nonlinear absorption), and it based on a single beam method where the sample puts at a place in parallel with the Gaussian beam, then distortion occurs on the wave front due to Kerr effect (4).

Z-Scan is working in two parts: - PART I: The barrier in front of the detector (closed aperture) to measure the nonlinear of refractive index $\left(\mathrm{n}_{2}\right)$.PART II: In this part has been lifted barriers in front of the detector (open - aperture) for measuring the coefficient of nonlinear absorption $(\beta)$, (Fig.1) shows the setup of Z-scan.

Organic dyes are unsaturated hydrocarbon compounds with complex compositions. These dyes are classified according to the range of the wavelengths that emitted (5) characterized by a narrow and a wide range that can be tuned and possess high fluorescence output, so nonlinear coefficients can be observed very clearly. The most common of these dyes is Rhodamine $6 \mathrm{G}\left(\mathrm{C}_{28} \mathrm{H}_{31} \mathrm{~N}_{2}\right.$ 
$\mathrm{O}_{3} \mathrm{Cl}$ ) which belongs to the Xanthenes' family, it having a wide spectral range that can be tuned (broad toning). A number of double bonds characterize the molecular structure of this pigment, which is the secret of the effectiveness of these substances. It has a large cross-section of absorption in the visible spectrum in comparison to the other types of pigments (6).

Polymethylmethacrylate $\quad-\quad$ Acrylic (PMMA) are transparent, a colorless plastic material with a high degree softness and no crystalline due to the presence of the compensated side groups and the molecular structure of the monomer with the repeated polymerization unit (7). The refractive index equal to1.49 and its absorption spectrum are lying in the ultraviolet region. The absorption strength reaches $15 \%$ at the wavelength $200 \mathrm{~nm}$, and it is important to use it with organic dyes to improve dye lasers (8).

The aim of this work is study the effect of cold plasma on the spectral properties (absorbability and transmittance) and the nonlinear optical properties of polymeric polymers (PMMA) doped with R3Go pigment.

\section{Material and Methods:}

The dye Rhodamine (R3Go) with a purity 99.99\%.from HIMEDIA Company is used (the chemical formula $\mathrm{C}_{26} \mathrm{H}_{27} \mathrm{~N}_{2} \mathrm{O}_{3} \mathrm{Cl}$ ) with solvent is chloroforming $\mathrm{CHCl}_{3}$. The polymer that used in this study is Polymethylmethacrylate - Acrylic (PMMA) which is a transparent, colorless crystalline that can affect the physical properties of the synthesized of laser medium .The membranes have been prepared by a polymerization method, where taking a percentage of the polymer and adding to a percentage of solvent solution in the same solvent (chloroform). It is pour into a glass mold and left to dry and harden.

The Meter tech used to measure absorbance and permeability spectra. The thickness of the membranes was measure by using a German-built Coating Thickness. The Z-Scan system is composing of two parts: The Nd-YAG laser with wavelength of $1064 \mathrm{~nm}$ and $1 \mathrm{mw}$ power. Detector with lens have focal length $20 \mathrm{~cm}$, Fig. 1 .

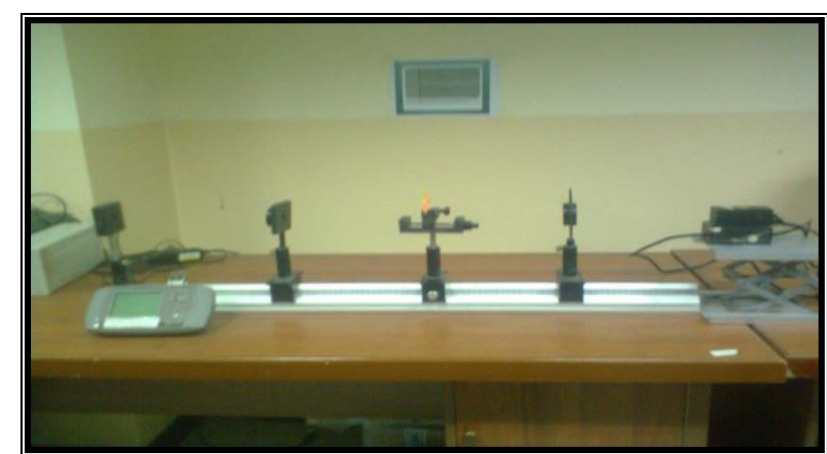

Figure 1. Z-scan setup

\section{Plasma system}

The plane Dielectric Barrier Discharge (DBD) has been use in this research to produce cold plasma and makes a treatment to the prepared polymeric membranes, (Fig. 2).

This system consists of two electrodes made from stainless steel with diameter $5 \mathrm{~cm}$ covered by Teflon with thickness $1 \mathrm{~cm}$ which represent the insulator material of the system .This is intending to prevent direct discharge between the two poles. The dielectric barrier discharge usually requires high alternating voltage ranging from 1-30 $\mathrm{kV}$ with frequency up to several kilohertz. In our experience the measured sample put on the lower electrode, the distance between upper electrod and the sample was $1 \mathrm{~mm}$, and the discharge voltage was $11 \mathrm{kV}$.



Figure2.shows DBD system

\section{Results and Discussion:}

Effect of plasma on the spectral properties of polymeric membranes:

The spectral properties (transmittance and absorption) of polymeric membranes (PMMA) with R3Go melted in chloroform at $5 \times 10^{-5} \mathrm{~mol} / 1$ and fixed thickness $272.5 \mu \mathrm{m}$ before and after exposure to plasma and at different exposure times 5,10, and 15 min where studied in more details.

Figure 3 Shows that the transmittance (T \%) before exposure to plasma is equal to (11.2) and 
equal to $(25,16.3,36.5)$ after exposure to plasma at time 5, 10 and $15 \mathrm{~min}$ respectively. It illustrated from Fig. (3). That the transmittance is increasing after exposure to plasma with a small shift appears at peak position of transmittance towards short wave length for 10-and15 mint and no shift happen at five mints. This means that changes have been made in the physical properties so that the sample becomes more transparent(9). On the other hand Fig.4 shows the absorbance of the polymer (PMMA) doped with a Rhodamine (R3GO) before and after exposure to plasma for different exposure times 5, 10, $15 \mathrm{~min}$.

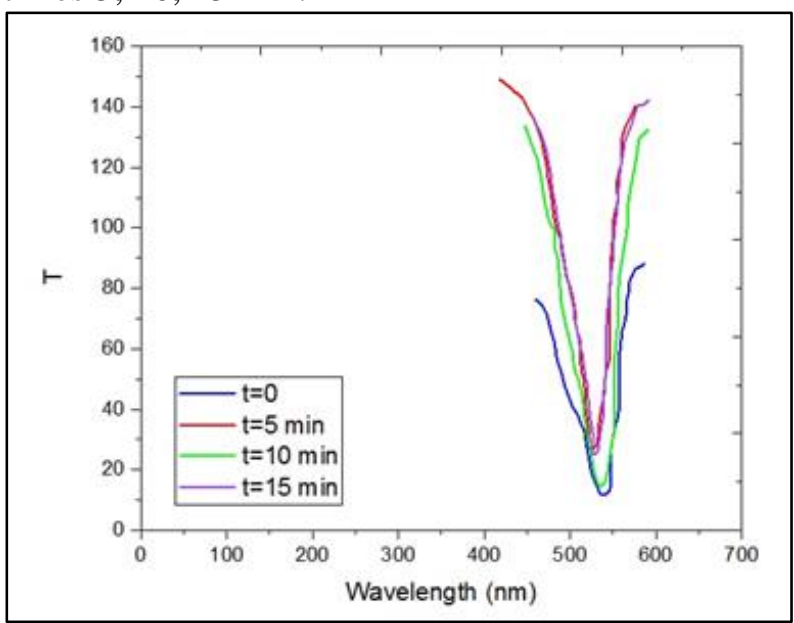

Figure 3. Shows the transmittance of the polymer sample (PMMA) doping with Rhodamine (R3GO) before and after exposure to plasma and for different times 5, 10, 15 min.

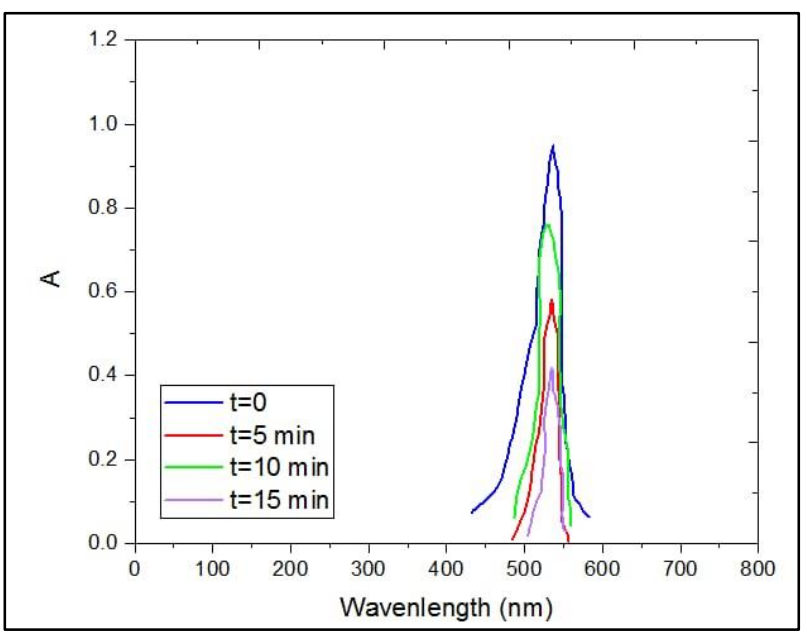

Figure 4. Shows the absorbance of the polymer model (PMMA) doping with Rhodamine (3GO) before and after exposure to plasma and for different times 5, 10, and $15 \mathrm{~min}$.
Effect of cold plasma on the nonlinear optical properties of polymerized membrane (PMMA):

The effect of cold plasma on the nonlinear optical properties of polymerized membrane (PMMA) has been study by comparing the samples before and after exposure to plasma. In addition, observing the effect of time factor by taking different time 5, 10, and 15 min, Fig .5 show the closed-aperture Z-scan curves. It's clear from this figure that the two dips representing non linearity finding closer to at point $\mathrm{z}=0$, where we have the highest and lower intensity. As matter of fact the 15 mint exposure dip along the positive side of $\mathrm{z}$ become much closer to that of the dip of the negative side of $z$. This may be interpreting as opposability of a miss aliment of the detector or uneven distribution of the intensity over the profile of the laser beam cross-section $(10,11)$.

The nonlinear refractive index $\mathrm{n}_{2}$ of the membranes has been calculating by using the following equations $(11,12)$ :

$$
\begin{aligned}
& n_{2}=\Delta \Phi_{0} / I_{0} L_{\text {eff }} k \ldots 1 \\
& \Delta T_{\mathrm{p}-\mathrm{v}}=0.406\left|\Delta \Phi_{0}\right| \quad \ldots \quad 2
\end{aligned}
$$

where $\Delta \mathrm{T}_{\mathrm{p}-\mathrm{v}}$ : the difference between the normalized peak and valley transmittances

$\Delta \Phi$ : nonlinear phase shift; $\mathrm{L}_{\text {eff: }}$ the effective thickness of the sample which calculated by using the following relationship:

$$
\mathbf{L}_{\text {eff }}=\left(1-\exp -\alpha_{0} L\right) / \alpha_{0} \quad \ldots 3
$$

Figure (6) show the open-aperture Z-scan curves to calculate the nonlinear absorption coefficient $(\beta)$ of the membranes using the following equations (13):

$$
\begin{aligned}
& T_{(z)}=1-q_{0} / 2 \sqrt{ } 2 \quad \ldots \quad 4 \\
& q_{0}=I_{0} L_{\text {eff }} \beta[1+z] \ldots 5
\end{aligned}
$$

where: $\mathrm{T}_{\text {(Z) }}$ the sample transmittance; Z: sample position and $\mathrm{I}_{0}$ is the intensity of the laser beam at focus $\mathrm{z}=0$. Figure 6 has the same behavior which the non-linearity increasing after exposure to the plasma and the two dips also became closer to $\mathrm{z}=0$ at the15 mint exposure $(11,12,13)$. 

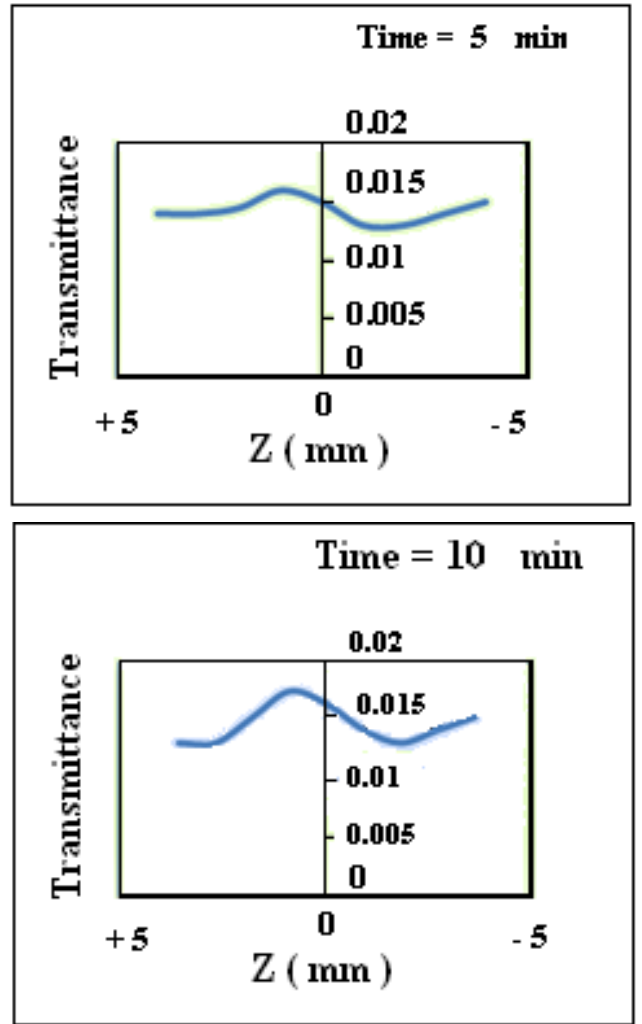
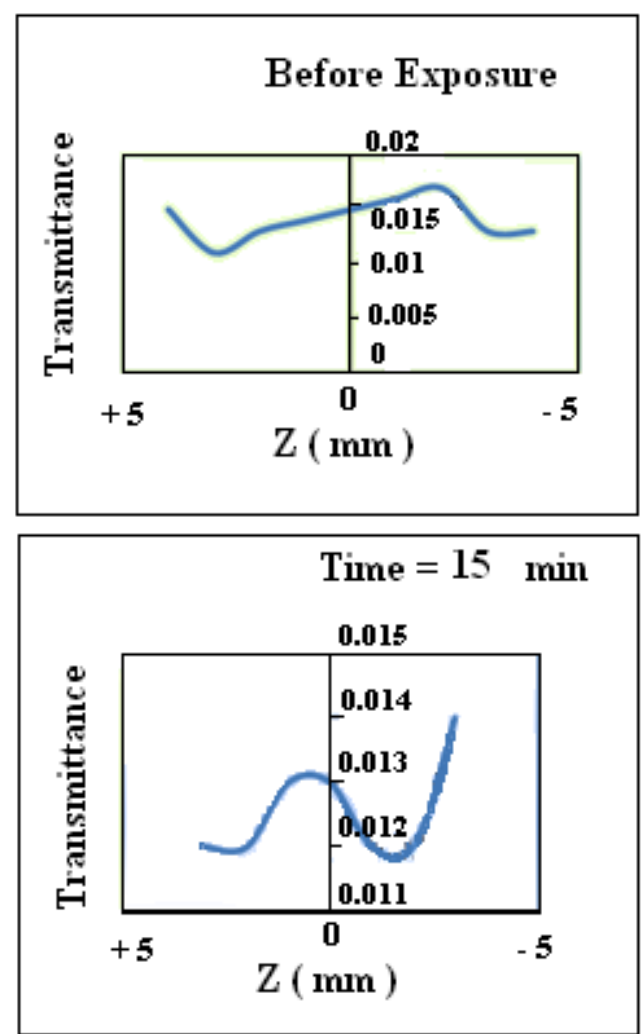

Figure 5. Shows the curves (closed-aperture Z-scan) of the polymer membrane (PMMA) doping with Rhodamine (R3GO) before and after exposure to plasma at different times $(5,10$ and 15) min.
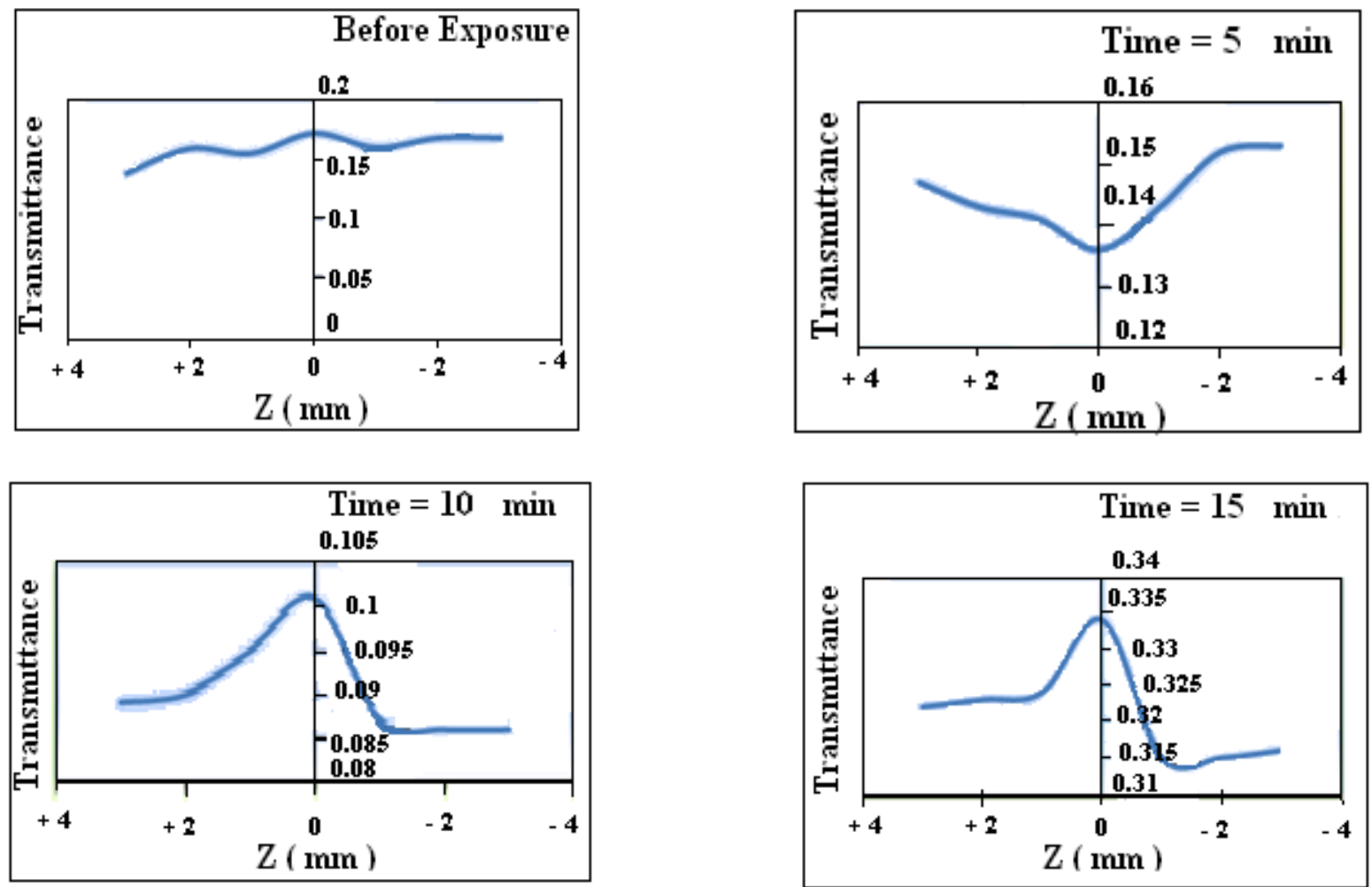

Figure 6. Shows (open-aperture Z-scan) curves of the polymer membrane (PMMA) doping with Rhodamine (R3GO) before and after exposure to plasma and for different times (5, 10 and 15) $\mathrm{min}$.

Table 1. illustrated the nonlinear of refractive index $n_{2}$ and the absorption coefficient $\beta$ were changing by increasing the time of plasma exposure, as shown in Figs. 7, 8. One can conclude from this table that plasma has an effect on nonlinear properties by affecting the composition of the polymer $(9,14)$. 
Table 1. Shows the linear and nonlinear variables of polymer membrane (PMMA) doping with Rhodamine (R3GO) before and after exposure to plasma and for different times.

\begin{tabular}{lllllllll}
\hline Time (min) & $\mathbf{T} \%$ & $\boldsymbol{\alpha}_{\mathbf{0} \times 10}{ }^{-5} \mathbf{~}^{-1}$ & $\mathbf{L}_{\text {eff x10 }}{ }^{-3}$ & $\Delta \mathbf{\Phi}_{\mathbf{0}}$ & $\mathbf{n}_{\mathbf{2}} \mathbf{x 1 0}$ & $\mathbf{n}_{\mathbf{2}}$ type & $\mathbf{T}_{(\mathbf{z})}$ & $\mathbf{B} \mathbf{~ c m} / \mathbf{m w}$ \\
\hline $\begin{array}{l}\text { Before exposure } \\
\text { to plasma }\end{array}$ & 11.2 & 8.032 & 0.11 & 0.039 & 2.93 & $+\mathrm{ve}$ & 0.172 & 208.08 \\
$\mathbf{5}$ & & & & & & & & \\
$\mathbf{1 0}$ & 25 & 5.072 & 1.47 & 0.032 & 1.809 & $+\mathrm{ve}$ & 0.136 & 163 \\
$\mathbf{1 5}$ & 16.3 & 6.655 & 1.25 & 0.034 & 2.24 & $+\mathrm{ve}$ & 0.101 & 198 \\
\hline
\end{tabular}

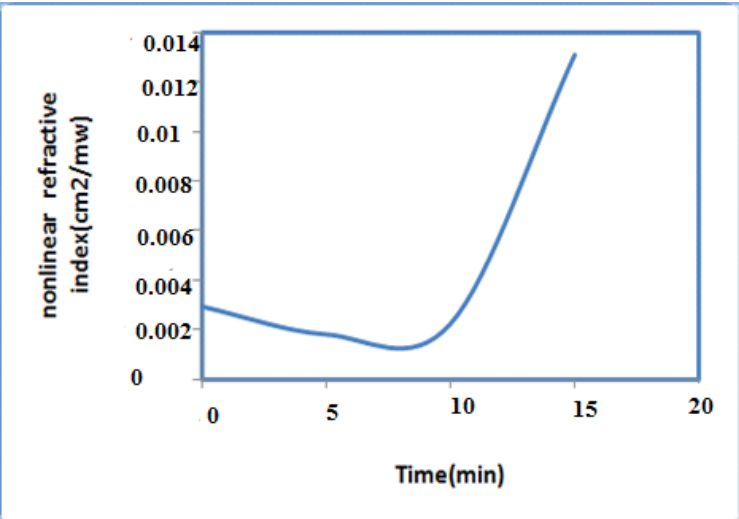

Figure 7. Shows the relationship between the nonlinear refractive index $n_{2}$ and the time of the Polymer membrane (PMMA) doping with Rhodamine (R3GO).

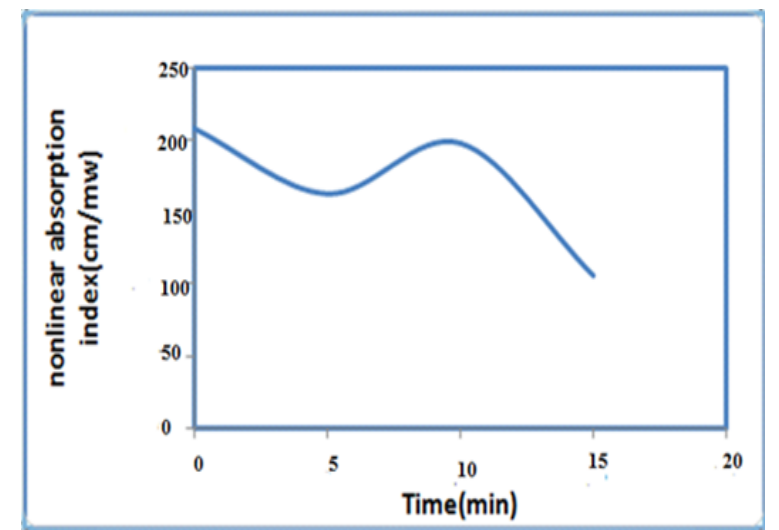

Figure 8. The relationship between the nonlinear absorption coefficient $\beta$ and the time of the polymer membrane (PMMA) doping with Rhodamine (R3GO).

\section{Conclusion:}

Large optical nonlinearity in the polymer membrane (PMMA) doping with Rhodamine (R3GO) have been observed using pulse Nd:YAG when exposure to the plasma at different time. The nonlinear refractive index $\mathrm{n}_{2}$ and the absorption coefficient $\beta$ are both changes, which gives a good indication about the effect of plasma on the internal structure of the polymer. The large optical nonlinearities have been caused by two-photonresonant exaction in the samples. Finally, it could be pointed out that these samples are fabricated by normal polymerization method.

\section{Conflicts of Interest: None.}

\section{References}

1. Martin M. From distant stars to dental chairsPlasmas MayPromise Pain-free and durable Restorations. AGD Impact. 2009..37-46.

2. Hoffmann C, Berganza C, Zhang J. Cold. Atmospheric Plasma: methods of production and application in dentistry and oncology. Med Gas Res.2013 Oct;3(21):1-15.

3. Trager F.Handbook of Lasers and Optics. $2^{\text {nd }}$ ed. Springer.2007.

4. Khoo IC. Nonlinear optics, active plasmonics and metamaterials with liquid crystals. Prog quant electron . 2014 Mar 1;38(2):77-117.

5. Choubey RK, Medhekar S, Kumar R, Mukherjee S, Kumar S. Study of nonlinear optical properties of organic dye by Z-scan technique using He-Ne laser. J Mater Sci: Mater Electron. 2014 Mar 1;25(3):14105.

6. Sadik Z. . Energy Transfer of Laser Dyes with polymer thin films. Ph.D. Thesis, University of Baghdad;2002.

7. Butcher DJ. Atomic fluorescence spectrometry: A review of advances in instrumentation and novel applications. Appl spectrosc Rev. 2016 May 27; 51(5):397-416.

8. Raeda J. Hamoud Al-Hamdani, Spectral and Categorical Study of the Laser Center for Effective Creditors. Master Thesis, University of Baghdad.2006.

9. Dorranian D, Golian Y, Hojabri A. Investigation of nitrogen plasma effect on the nonlinear optical properties of PMMA. JTAP. 2012 Dec 1;6(1):1-8

10. Shaima Kh. Spectroscopic Study of Polymer (PMMA) Dopped with both Rhodamin Dyes RC, RB and their mixture. Master Thesis, University Of Baghdad.2012.

11. Al-Hamdani AH, Ibrahim SI, Jawad RS, Nader R, Adnan D, Jabir M. Non-linear Properties Measurement for Liquid Solution of $\alpha$-Chlorophyll Dissolved in Acetone. IJOCAAS. 2016 Oct;1(2):2836.

12. Nader T, The Study of Non-Linear Properties for Fluorescein Sodium Dye in Water .IJSR .2017 Jan;6 (1):2279-81.

13. Nader R, Al-Hamdani AH, Ibrahim SI, Ullah RA.. Non-linear properties for Membranes of Rhodamine tincture by using Z-Scan Technique. IJAIEM 2015 Sep; 4(9): 52-57.

14. Castillo-Torres J, Hernández A, González-Martínez S, Aguirre-Lopez A, Hernandez MB, AguilarMartínez JA. Self-focusing in chromium-doped potassium niobate single ceramic crystal. REV MEX FIS. 2006 Dec;52(6):540-5. 
دراسة تاثير البلازما الباردة على الخصائص اللاخطية لبوليمر المطعم بصبغة الرودامين (R3GO)

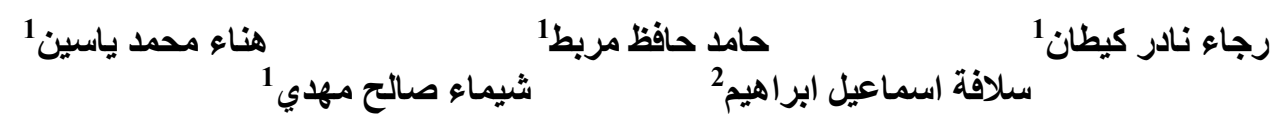

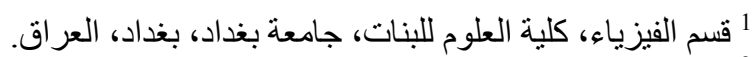

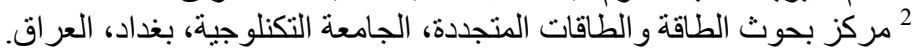

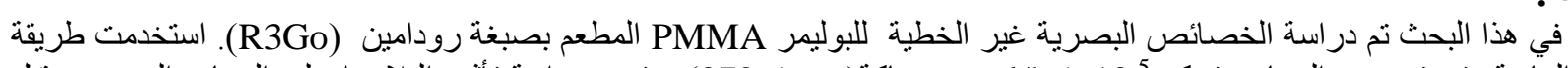
الخلاصة:

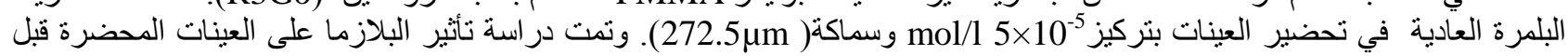

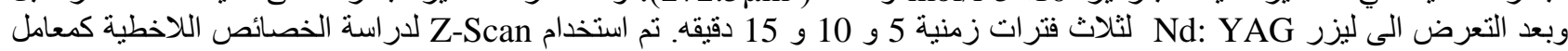

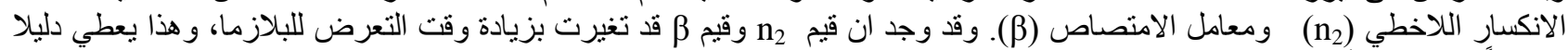
و اضحاً على مدى تأثثير البلازما على التركيب الداخلي اللبوليمر. الكلمات المفتاحيه: تفريغ الحاجز العازل، ليزر النديميوم -ياك، الصفات اللاخطيه ،الماسح الضوئي ئلاثي الابعاد. 